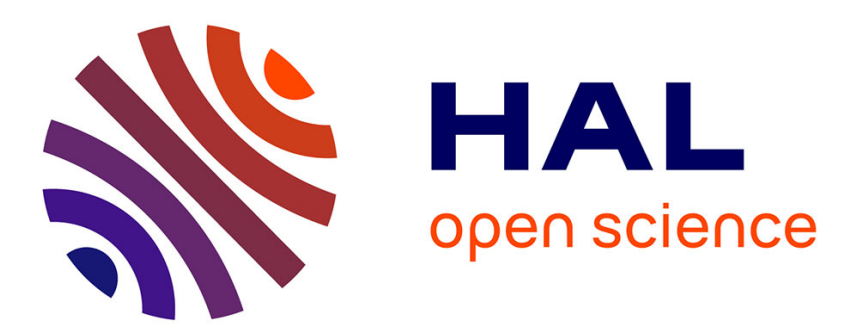

\title{
Thermal transfer simulation regarding the rotational moulding of polyamide 11
}

\author{
Said Lofti Hafsaoui, Mokhtar Benziane, Abbas Tcharkhtchi
}

\section{To cite this version:}

Said Lofti Hafsaoui, Mokhtar Benziane, Abbas Tcharkhtchi. Thermal transfer simulation regarding the rotational moulding of polyamide 11. Journal of Thermal Analysis and Calorimetry, 2013, 112 (1), pp.285-292. 10.1007/s10973-012-2806-4 . hal-00984690

\section{HAL Id: hal-00984690 https://hal.science/hal-00984690}

Submitted on 30 Apr 2014

HAL is a multi-disciplinary open access archive for the deposit and dissemination of scientific research documents, whether they are published or not. The documents may come from teaching and research institutions in France or abroad, or from public or private research centers.
L'archive ouverte pluridisciplinaire HAL, est destinée au dépôt et à la diffusion de documents scientifiques de niveau recherche, publiés ou non, émanant des établissements d'enseignement et de recherche français ou étrangers, des laboratoires publics ou privés. 


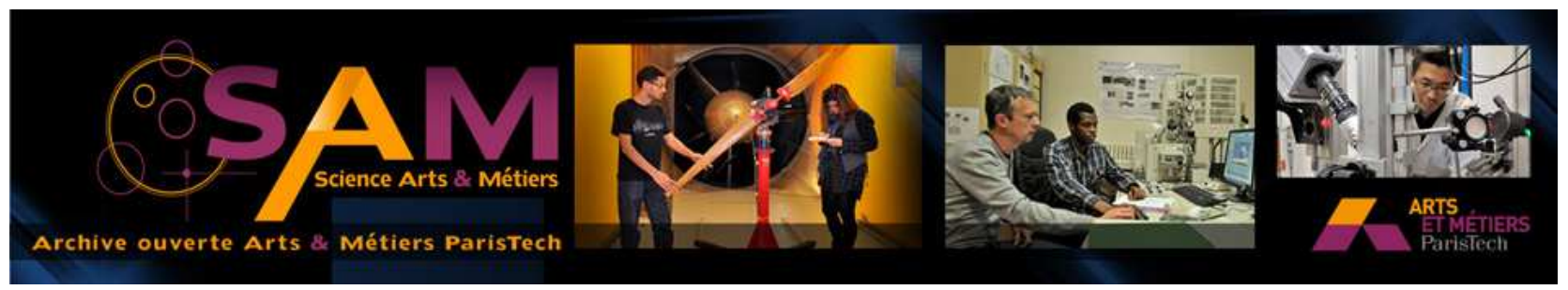

Science Arts \& Métiers (SAM)

is an open access repository that collects the work of Arts et Métiers ParisTech researchers and makes it freely available over the web where possible.

This is an author-deposited version published in: http://sam.ensam.eu Handle ID: .http://hdl.handle.net/10985/8055

\section{To cite this version :}

Said Lofti HAFSAOUI, Mokhtar BENZIANE, Abbas TCHARKHTCHI - Thermal transfer simulation regarding the rotational moulding of polyamide 11 - Journal of Thermal Analysis and Calorimetry Vol. $112, n^{\circ} 1$, p.285-292 - 2013 


\title{
Thermal transfer simulation regarding the rotational moulding of polyamide 11
}

\author{
Said Lotfi Hafsaoui • Mokhtar Benziane • \\ Abbas Tcharkhtchi
}

\begin{abstract}
Simulation of thermal phenomena in rotational moulding is very important to follow the evolution of the temperature in various zones of this process. It was a question of modelling heat gradients developing in rotational moulding part. Thermal model tested take into account the temperature change (thermal transfer mechanism) of melting and crystallization pseudo-stages (enthalpy method). Series of tests in polyamide 11 (PA11) were carried out by means of rotational moulding STP $\mathrm{LAB}$, and non-isothermal crystallization kinetics of rotational moulding PA11 grade are measured and analysed by DSC technique type TAQ20. A result of non-isothermal crystallization of the studied polyamide was confronted with Ozawa model. In order to test the validity degree of enthalpy method (layer to layer), another approach based on Ozawa model has also been used in the case of cooling pseudo-stage. As results, the rotational moulding of PA11 was successfully carried out. The simulation of the fusion and crystallization stages, by application of Ozawa model coupled with enthalpy method gave a good representation of experimental data.
\end{abstract}

Keywords Rotational moulding · Polyamide 11 . Thermal simulation · Ozawa model $\cdot$ Enthalpy method

S. L. Hafsaoui · M. Benziane

Laboratoire de Génie des Procédés, Ecole Militaire

Polytechnique, BP 17, 16111 Bordj El Bahri, Algeria

S. L. Hafsaoui · A. Tcharkhtchi $(\bowtie)$

PIMM (UMR-CNRS 8006), Arts et Métiers Paris Tech,

151 boulevard de l'Hôpital, 75013 Paris, France

e-mail: abbas.tcharkhtchi@ensam.eu

\section{Introduction}

Nowadays, rotational moulding polymer process is considered as the fastest growing sector of the plastics processing industry [1]. It is an economical manufacturing method for producing large or small, stress-free, one piece, and hollow plastic articles [2-6]. Rotational moulding differs from all conventional processing methods especially in heating, and cooling stages which are occurring after the polymer is placed in the mould, and no external pressure is applied.

The development of this process is possible by considering the manufacture of technical parts, satisfying requirements of many sectors like automotive, civil engineering, sport and leisure. In certain applications, rotational moulding becomes an interesting alternative to stretch blow moulding [7, 8]. Many research works were launched to better including, understanding and optimising the various stages of transformation [9-13].

The principal disadvantage of rotational moulding, compared to conventional techniques, is the relatively long cycle time. Polymer is carried during several tens of minutes in a molten state at high temperature with the presence of air. Therefore, the polymer material can be affected by the thermal degradation risk.

This paper is devoted to the study of thermal model predicting temperature variation at any point of the polymer part in development stages.

Thermal simulation of heat phenomena in rotational moulding must pass by a better comprehension of complex mechanisms which govern various stages of transformation.

However, in this process, study of these mechanisms is very difficult, because in reality, temperature is not constant and is characterised by certain heterogeneity. In rotational moulding, thermal cycle is schematically composed of two 
stages: a heating stage followed by a cooling. These stages do not occur at constant rate, and each one comprise a pseudo-stage generated by a phase changes corresponding to fusion and crystallization.

This study is divided into two main parts, the first one is focused on the rotational moulding of polyamide 11 , and the second one is devoted to simulation of thermal transfer phenomenon in rotational moulding and modelling of phase changes by enthalpy method [14-16] coupled to Ozawa model [17]. The results obtained allow us to validate the theoretical approach adopted by the experimentation and to observe that the two shutters (theoretical and experimental) are closely dependant.

\section{Experimental}

Materials and preparation

The polymer under study, supplied by Akrema INC, is an aliphatic Polyamide (PA11) as powder. For the reason of the hydrophilic character of this polyamide, all samples were dried in a vacuum oven at $80{ }^{\circ} \mathrm{C}$ for $8 \mathrm{~h}$ before use. Curve obtained by differential scanning calorimetry (under $\mathrm{N}_{2}$ at $10{ }^{\circ} \mathrm{C} \mathrm{min}{ }^{-1}$ ) gives a melting point $T_{\mathrm{f}}$ at $186{ }^{\circ} \mathrm{C}$, a crystallization temperature $T_{\mathrm{C}}$ at $162{ }^{\circ} \mathrm{C}$, a melting enthalpy $H_{\mathrm{m}}$ of $49 \mathrm{~J} \mathrm{~g}^{-1}$ and a crystallization enthalpy $H_{\mathrm{C}}$ of $38 \mathrm{~J} \mathrm{~g}^{-1}$.

\section{Method}

\section{Rotational moulding and correcttemp measurement}

A spherical PA11 parts of 2-mm thickness was processed in an aluminium mould of 5-mm thickness and inner diameter of $78 \mathrm{~mm}$, with a rotational moulding machine shuttle STP LAB40 equipped by an electrical furnace maintained at a constant temperature of $350{ }^{\circ} \mathrm{C}$. Corresponding processing conditions are given in Table 1.

During the processing operations, the internal air temperature $T_{\mathrm{a}}$ was measured in the centre of the mould with a temperature sensor (CorrectTemp). The average rate was about $10{ }^{\circ} \mathrm{C} \min ^{-1}$ for heating stage and about $20{ }^{\circ} \mathrm{C} \mathrm{min}{ }^{-1}$ for cooling stage.

\section{Differential scanning calorimetry measurements}

Thermal analysis of the samples was performed using a DSC TAQ20. All tests were performed under nitrogen atmosphere with a sample mass range between 5 and $8 \mathrm{mg}$. All samples were heated quickly to $220{ }^{\circ} \mathrm{C}$, above the melting temperature at a rate of $10{ }^{\circ} \mathrm{C} \min ^{-1}$ and kept for 10 min to eliminate prior thermal history. Then, the sample was cooled down to ambient temperature at various cooling rate: $5,7,10,12,15,18$ and $20{ }^{\circ} \mathrm{C} \mathrm{min}{ }^{-1}$. The exothermic curves of heat flow were recorded and investigated.

\section{Results and discussion}

Temperature measurement during rotational moulding

By following the temperature variation inside the mould as shown on the Fig. 1, we could differentiate six principal stages:

- Up to point $a$, mould and polymer is still cold, the polymer has not yet reached its melting point (the powder form is maintained). Once the heat passes (from oven) through mould into its interior part, the internal temperature increases at constant rate.

- At point $a$, the polymer melting point is reached into the interior part of the mould. A first grain powder adheres to mould and the heating rate decreases, due to insulating character of polymer.

- At point $b$, all grains powder is melted and the temperature increases quickly. A maximum temperature is selected to give a time and sufficient fluidity to polymer for a homogeneous distribution. The choice of this temperature is important to avoid polymer thermal degradation. In this study, we cannot exceed the maximum temperature of $280{ }^{\circ} \mathrm{C}$, temperature beyond which the risks of thermolysis of hydrocarbon polymers become significant [6, 7, 18, 19]. As an example, a maximum temperature of internal air was $245^{\circ} \mathrm{C}$ for a $20 \mathrm{~min}$ heating time and $275^{\circ} \mathrm{C}$ for a 30 min heating time, in both cases with oven maintained at $350{ }^{\circ} \mathrm{C}$.

- At point $c$, heating is stopped. Mould in rotation leaves oven to enter in cooling room. Temperature decreases linearly up to point $d$.

- At point $d$, polymer begins its solidification. Cooling rate decreases under crystallization exothermic effect and finishes at point $e$, where the molecular movements become very slow and the end of crystallization is reached.

- At point $f$, part is unmoulded.

Table 1 Rotational moulding operating conditions

\begin{tabular}{llll}
\hline Heating time/min & Cooling time/min & Rotational speed around axis 1/rpm & Rotational speed around axis 2/rpm \\
\hline 30 & 20 & 9.6 & 4 \\
\hline
\end{tabular}




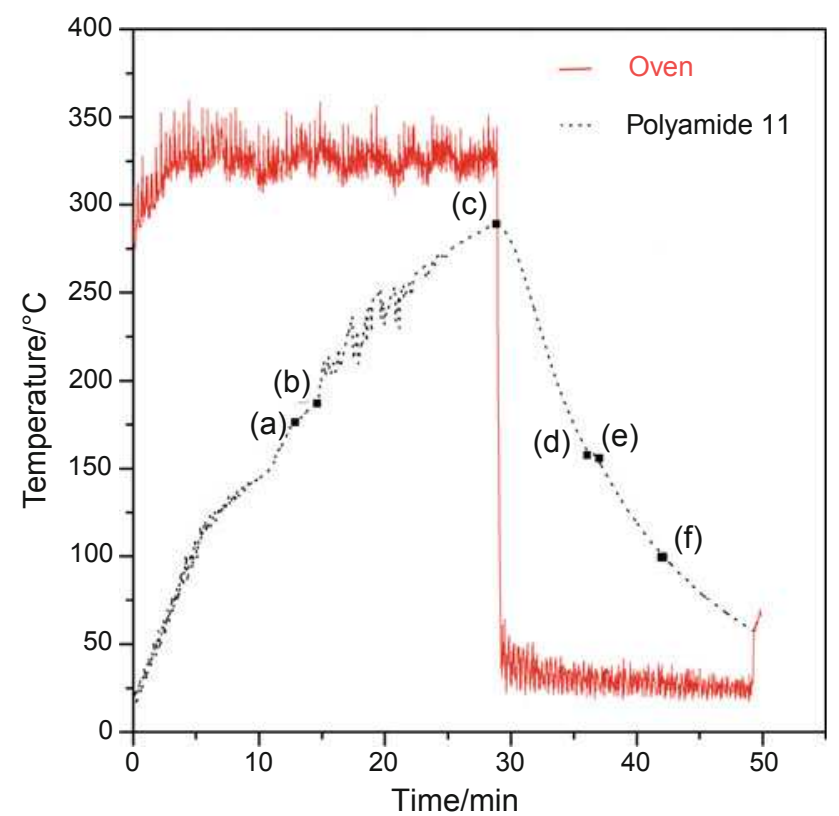

Fig. 1 Temperature versus time, (T/t) diagram of PA 11. Various points indicate: $(a)$ fusion of 'elementary' layer of polymer powder in contact with mould internal surface; $(b)$ fusion of 'elementary' layer furthest away from mould surface; $(c)$ end of heating and cooling beginning; $(d-e)$ polymer crystallization; $(f)$ end of rotational moulding

Non-isothermal crystallization behaviour

Figure 2 shows typical non-isothermal crystallization curves of PA11 for different cooling rates.

These results are recapitulated in Table 2 in which the following parameters are determined:

- Onset temperature of crystallization $T_{0}$, crystallization temperatures (the exothermic peak maxima) $T_{\mathrm{p}}$,

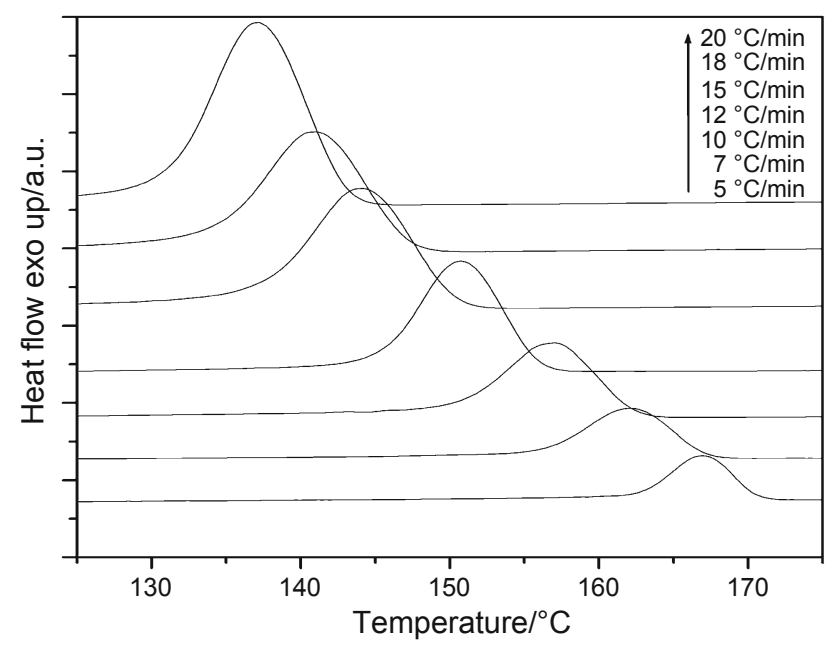

Fig. 2 DSC curves of non-isothermal crystallization at different cooling rates of PA11
Table 2 Values of $\Delta H_{\mathrm{C}}, T_{0}, T_{\mathrm{P}}$ and $t_{\mathrm{P}}$ at various cooling rates for rotational moulding PA6 grade

\begin{tabular}{|c|c|c|c|c|}
\hline$\phi /{ }^{\circ} \mathrm{C} \min ^{-1}$ & $\Delta H_{\mathrm{C}} / \mathrm{J} \mathrm{g}^{-1}$ & $T_{0} /{ }^{\circ} \mathrm{C}$ & $T_{\mathrm{P}} /{ }^{\circ} \mathrm{C}$ & $T_{\mathrm{P}} / \min$ \\
\hline 5 & 39.45 & 171.44 & 167.15 & 0.86 \\
\hline 7 & 39.21 & 168.04 & 162.59 & 0.78 \\
\hline 10 & 38.79 & 163.38 & 156.95 & 0.64 \\
\hline 12 & 38.64 & 157.41 & 150.79 & 0.55 \\
\hline 15 & 38.22 & 151.58 & 144.27 & 0.48 \\
\hline 18 & 38.01 & 148.56 & 141.14 & 0.41 \\
\hline 20 & 37.95 & 145.18 & 137.29 & 0.39 \\
\hline
\end{tabular}

crystallization enthalpy $\Delta H_{\mathrm{C}}$, crystallization peak time $t_{\mathrm{p}}$, interval time between $T_{0}$ and $T_{\mathrm{p}}$.

These results call the following comments:

- $T_{0}$ and $T_{\mathrm{p}}$ decrease by increasing cooling rate.

- The peak is widened when the cooling rate is more important.

- The crystallization rate depends on the cooling rate that means $\Delta H_{\mathrm{C}}$ is inversely proportional to the cooling rate.

Ozawa version analysis

From results depicted on Fig. 2, we can follow the relative degree of crystallinity, $X_{\mathrm{T}}$, as a function of temperature using the following equation:

$X_{\mathrm{T}}=\frac{\int_{T_{0}}^{T}\left(\mathrm{~d} H_{\mathrm{C}} / \mathrm{d} T\right) \mathrm{d} T}{\int_{T_{0}}^{T_{\infty}}\left(\mathrm{d} H_{\mathrm{C}} / \mathrm{d} T\right) \mathrm{d} T}$,

where, $\mathrm{d} H_{\mathrm{c}} / \mathrm{d} T$ is the heat flow rate. $T_{0}$ and $T_{\infty}$ are the temperatures at which crystallization starts and finishes. Figure 3 shows the relative degree of crystallinity versus the temperature.

Ozawa proposed a theory [17] to calculate crystallinity rate, $X_{\mathrm{t}}$, in the case of non-isothermal crystallization. The assumption lies on the fact that the relationship between growth rate and activation frequency of nucleation is constant during crystallization. This theory makes it possible to arrive at noted general expression:

$\log \left[-\ln \left(1-X_{\mathrm{t}}\right)\right]=\log K(T)-m \log \phi$,

where, $m$ is the index of Ozawa similar to Avrami exponent, $\phi$ is the cooling rate and $K(T)$ is the function of cooling rate.

The results obtained from non-isothermal crystallization of the studied polyamide are compared to Ozawa's model which allows quantifying by means of the Avrami coefficient (factor $m$ ), the type of nucleation (homogeneous or heterogeneous) and the geometry of growth. 


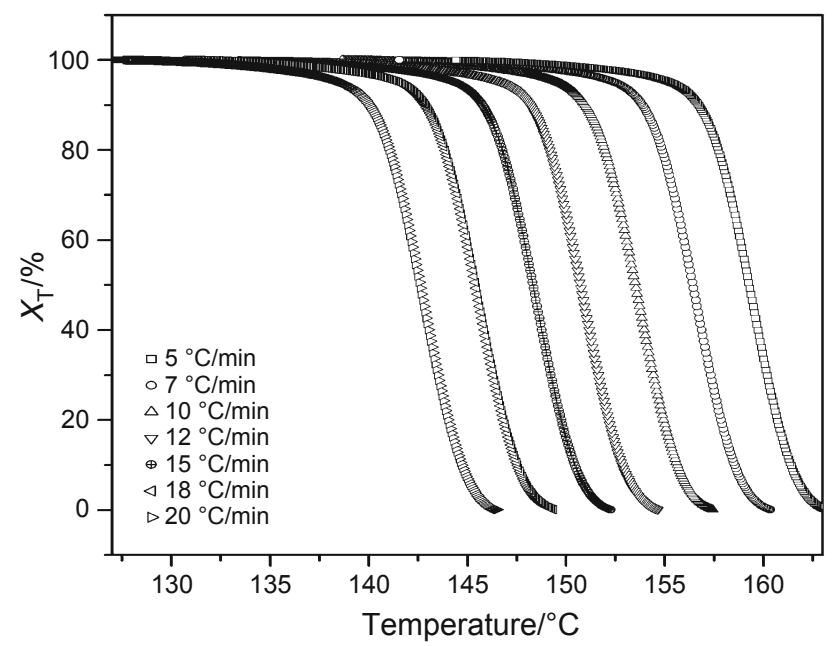

Fig. 3 Relative crystallinity versus temperature for non-isothermal crystallization of PA11

Figure 4 illustrates the plots of $\log \left[\ln \left(1-X_{\mathrm{t}}\right)\right]$ as a function of $\log \phi$.

A series of straight lines are obtained meaning that the Ozawa's model is appropriate for describing the nonisothermal crystallization kinetics in this kind of temperature range. Parameters $m$ and $K(T)$ can be obtained from the slope and the intercept of the line.

The $m$ and $\log K(T)$ at different temperatures are listed in Table 3.

We can thus evaluate the complexity of the mechanism of crystallization [20], because an intermediate situation is obtained between instantaneous nucleation $(m=2)$ and sporadic nucleation $(m=3)$, with two-dimensional crystallization geometry growth.

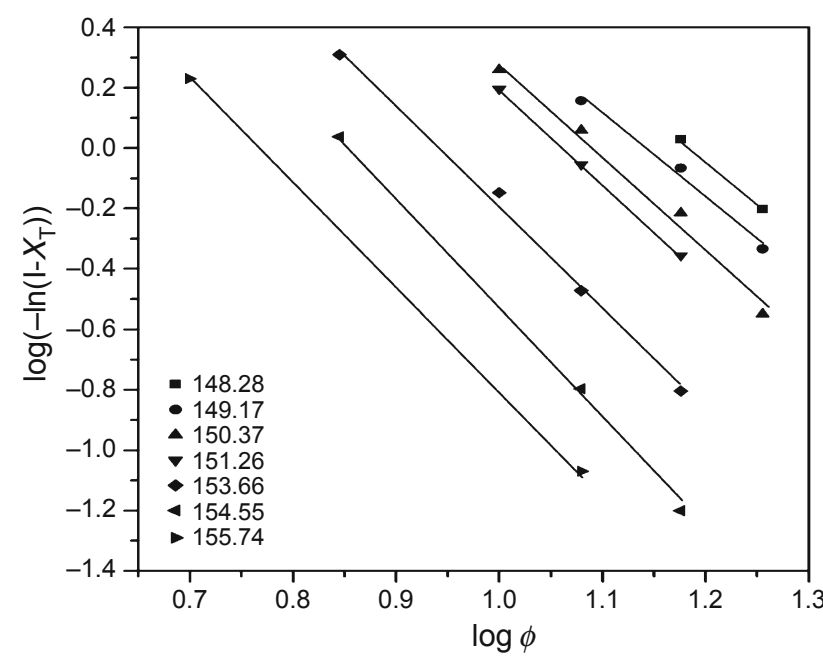

Fig. 4 Plots of $1 \log \left[-\ln \left(1-X_{\mathrm{r}}\right)\right]$ versus $\log \phi$, for PA11
Table 3 Non-isothermal crystallization parameters obtained by Ozawa method

\begin{tabular}{llcl}
\hline$T_{0}{ }^{\circ} \mathrm{C}$ & $m$ & $k(T) / \mathrm{K} \mathrm{min}^{-\mathrm{m}}$ & $R$ \\
\hline 155.75 & 3.71 & 427.74 & 0.9999 \\
154.55 & 3.41 & 638.52 & 0.9998 \\
153.66 & 3.38 & 694.13 & 0.9997 \\
151.26 & 3.13 & 1022.54 & 0.9996 \\
150.37 & 3.12 & 1548.81 & 0.9995 \\
149.17 & 2.91 & 2884.83 & 0.9989 \\
148.28 & 2.76 & 3027.11 & 0.9985 \\
\hline
\end{tabular}

Thermal simulation

Enthalpic method (layer by layer)

The general model represents heat exchange during rotational moulding, in which approximation of thermal transfer is one dimensional. On the basis of this report, Tcharkhtchi et al. [14] used a more adapted method to describe phase change. This method makes it possible to use only one equation to describe thermal phenomenon in both two phases (liquid polymer and solid powder), and makes it possible, thus, to free from the calculation of boundary conditions on liquid/solid interface. It is named enthalpy method $[15,16]$. If we leave the assumption that melting or crystallization does not occur at a constant temperature, which is more realistic for a particulate solid, enthalpy evolution according to temperature can be schematized as on Fig. 5. Considering two successive elementary sections (sections $(i)$ and $(i+1)$ ) in part in development. We observe that function $\mathrm{HF}=$ $f(T)$ in melting case consists of three lines:

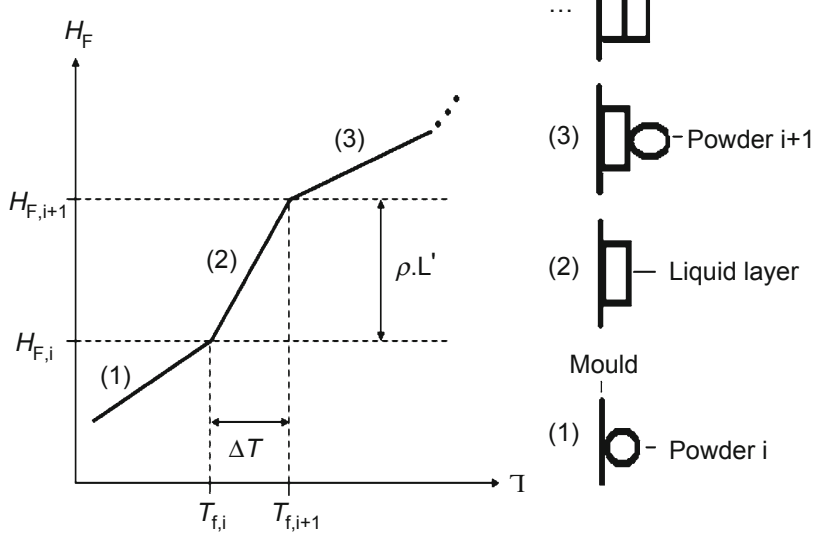

Fig. 5 Enthalpy evolution law according to temperature. Main parameters are: $T_{\mathrm{f}, \mathrm{i}}=$ initial fusion temperature of elementary layer (i); $T_{\mathrm{f}, \mathrm{i}+1}=$ initial fusion temperature of elementary layer $(i+1)$; $L^{\prime}=$ fusion latent heat and $\rho=$ solid polymer density 
(a) In field (1), as long as temperature did not reach melting point of layer ( $i$ ) (that is to say $T<T_{\mathrm{f}, \mathrm{i}}$ ), we can write:

$H_{\mathrm{F}}(T)=\rho_{\mathrm{ps}} C_{\mathrm{ps}}\left(T-T_{0}\right)+H_{0}$

where, $\rho_{\mathrm{ps}}$ and $C_{\mathrm{ps}}$ are, respectively, solid polymer density and solid polymer specific heat. $H_{0}$ is enthalpy reference value at reference temperature $\left(T=T_{0}=298 \mathrm{~K}\right)$.

(b) In field (2), temperature reached melting point of layer $i$ but not yet that of layer $(i+1)$ (either $T_{\mathrm{f}, \mathrm{i}}<T<T_{\mathrm{f}, \mathrm{i}+1)}$. We consider a linear variation of enthalpy according to temperature:

$H_{F}(T)=\frac{\rho_{\mathrm{ps}} L^{\prime}}{\Delta T}\left(T-T_{\mathrm{f}, \mathrm{i}}\right)+H_{\mathrm{F}, \mathrm{i}}$

where, $L^{\prime}$ is fusion latent heat and $H_{\mathrm{F}, \mathrm{i}} i$ layer melting enthalpy value. $\Delta T$ is the difference between the temperature of the two layers $(i$ and $i+1)$ and its expression is given by the following equation:

$\Delta T=T_{\mathrm{f}, \mathrm{i}+1}-T_{\mathrm{f}, \mathrm{i}}$

(c) In field (3), temperature reached melting point of layer $(i+1)$ (either $\left.T_{\mathrm{f}, \mathrm{i}+1}<T\right)$ :

$H_{\mathrm{F}}(T)=\rho_{\mathrm{pl}} C_{\mathrm{pl}}\left(T-T_{\mathrm{f}, \mathrm{i}+1}\right)+H_{\mathrm{F}, \mathrm{i}+1}$

where, $\rho_{\mathrm{pl}}$ and $C_{\mathrm{pl}}$ are, respectively, liquid polymer density and its specific heat. $H_{\mathrm{F}, \mathrm{i}+1}$ represents $(i+1)$ layer melting enthalpy value.

The differential equations that we could consider in numerical work are partial and of second order. In the literature we can list three adapted numerical methods [21-24]: explicit methods, Euler implicit and CrankNicholson method. On mathematical account of the simplicity, we adopted the second method [25]; the mould, the air and the studied polymer properties are given in Table 4 .

With help of finite differences method, thermal transfer equations can be written with discretization in unidirectional space by order 1 Euler implicit scheme. Space field of length $L$ is divided into $N$ elements of size $h_{\mathrm{x}}$ and temperature is evaluated in each one of $N$ nodes.

$h_{\mathrm{x}}=\frac{L}{N}$

Temperature is evaluated in $N$ nodes. The position of each node is described by:

$x_{\mathrm{i}}=\mathrm{ih}_{x}, i \in[1, N]$

Time is discretized as following:

$t_{\mathrm{k}}=k \Delta t, k \in\left[0, t_{\text {cycle }}\right]$

So conduction (for example) can be discretized by:
Table 4 Main characteristics of mould, air and polyamide 11

\begin{tabular}{lll}
\hline Properties & Value & Unit \\
\hline $\begin{array}{l}\text { Polyamide } 11 \text { characteristics } \\
\text { Heat of fusion } \Delta H_{\mathrm{m}} \text { at } 100 \% \text { of }\end{array}$ & $226^{\mathrm{c}}$ & $\mathrm{J} \mathrm{g}^{-1}$ \\
crystallinity & & \\
Crystallinity ratio, $\mathrm{X}_{\mathrm{C}}$ & $22.04^{\mathrm{a}}$ & $\%$ \\
Density, $\rho_{\mathrm{ps}}$ & $1,150^{\mathrm{b}}$ & $\mathrm{kg} \mathrm{m}^{-3}$ \\
Thermal conductivity, $k_{\mathrm{ps}}$ & $0.19^{\mathrm{d}}$ & $\mathrm{W} \mathrm{m}{ }^{-1} \mathrm{~K}^{-1}$ \\
Specific heat $C_{\mathrm{ps}}$ at $25^{\circ} \mathrm{C}$ & $1800.6^{\mathrm{a}}$ & $\mathrm{J} \mathrm{kg}^{-1} \mathrm{~K}^{-1}$ \\
Density, $\rho_{\mathrm{pl}}$ & $1,010^{\mathrm{b}}$ & $\mathrm{kg} \mathrm{m}^{-3}$ \\
Thermal conductivity, $k_{\mathrm{pl}}$ & $0.53^{\mathrm{b}}$ & $\mathrm{W} \mathrm{m}{ }^{-1} \mathrm{~K}^{-1}$ \\
Specific heat $C_{\mathrm{pl}}$ at $250^{\circ} \mathrm{C}$ & $2120.9^{\mathrm{a}}$ & $\mathrm{J} \mathrm{kg}^{-1} \mathrm{~K}^{-1}$ \\
Air characteristics & & \\
External air convection coefficient, $h_{\mathrm{fa}}$ & $25^{\mathrm{e}}$ & $\mathrm{W} \mathrm{m}{ }^{-2} \mathrm{~K}^{-1}$ \\
Internal air convection coefficient, $h_{\mathrm{pa}}$ & $05^{\mathrm{e}}$ & $\mathrm{W} \mathrm{m}{ }^{-2} \mathrm{~K}^{-1}$ \\
Air density, $\rho_{\mathrm{a}}$ & $01^{\mathrm{f}}$ & $\mathrm{kg} \mathrm{m}^{-3}$ \\
Internal air specific heat, $C_{\mathrm{pa}}$ & $1,010^{\mathrm{f}}$ & $\mathrm{J} \mathrm{kg}^{-1} \mathrm{~K}^{-1}$ \\
Mould characteristics & & \\
Mould density, $\rho_{\mathrm{mo}}$ & $2,700^{\mathrm{g}}$ & $\mathrm{kg} \mathrm{m}^{-3}$ \\
Mould thermal conductivity, $k_{\mathrm{mo}}$ & $218^{\mathrm{h}}$ & $\mathrm{W} \mathrm{m}{ }^{-1} \mathrm{~K}^{-1}$ \\
Mould specific heat, $C_{\mathrm{mo}}$ & $950^{\mathrm{h}}$ & $\mathrm{J} \mathrm{kg}^{-1} \mathrm{~K}^{-1}$ \\
\hline
\end{tabular}

${ }^{a}$ Our experimental values

b Technical data sheet

c Ref. [26]

${ }^{d}$ Ref. [27]

e Ref. [28]

${ }^{f}$ Ref. [29]

g Ref. [30]

${ }^{\mathrm{h}}$ Ref. [31]

$A \frac{T_{\mathrm{i}+1}^{\mathrm{k}}-2 T_{\mathrm{i}}^{\mathrm{k}}+{ }_{I-1}^{K}}{\Delta x^{2}}=\frac{T_{\mathrm{i}}^{\mathrm{k}}-T_{\mathrm{i}}^{\mathrm{k}-1}}{\Delta t} \quad \forall(\mathrm{i}, \mathrm{k})$

$A=\frac{k_{\mathrm{m}}}{\rho_{\mathrm{m}} c_{\mathrm{m}}}$

Where $k_{\mathrm{m}}$ is mould thermal conductivity, $\rho_{\mathrm{m}}$ is mould density and $c_{\mathrm{m}}$ is mould specific heat.

$-r T_{\mathrm{i}-1}^{\mathrm{k}}+(1+2 r) T_{\mathrm{i}}^{\mathrm{k}}-r T_{\mathrm{i}+1}^{\mathrm{k}}=T_{\mathrm{i}}^{\mathrm{k}-1}$

$r=A \frac{\Delta t}{\Delta x^{2}}$

Finally, discretization can be presented in matrix structure wherein each layer represents a matrix lineA non-empirical mathematical representation of thermal transfer in polymer could be written as: 


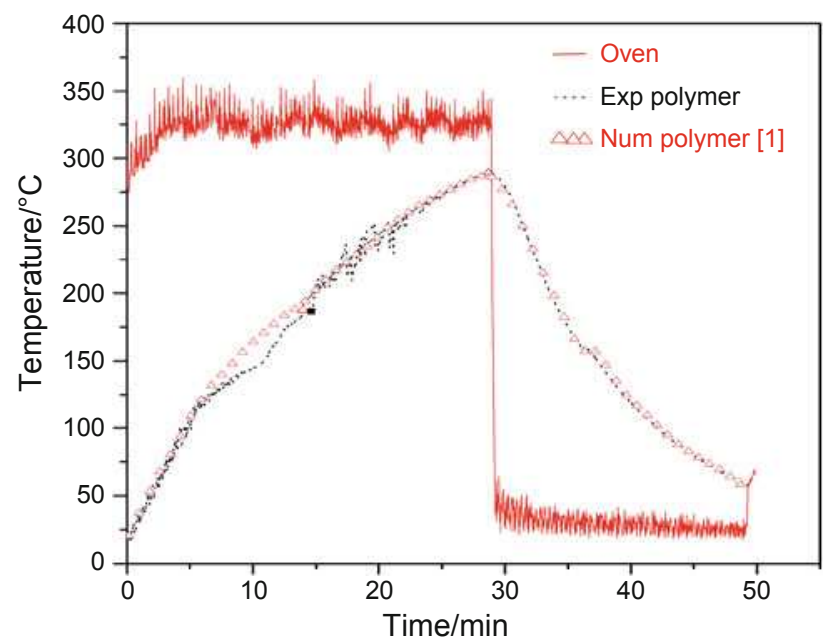

Fig. 6 Temperature versus time $(T / t)$ diagram of PA11 according to enthalpy method (layer to layer) and experimental one

$$
(1-\varepsilon) \rho_{p} \frac{\partial\left(C_{p} T\right)}{\partial t}+\Delta H=\frac{\partial}{\partial x}\left(k_{p} \frac{\partial T}{\partial x}\right)
$$

$\varepsilon$ is air fraction in polymer. It is, without any doubt, the most difficult parameter to evaluate. We will assume $\varepsilon=0 \% . \rho_{\mathrm{p}}$ and $C_{\mathrm{p}}$ are, respectively, polymer density and polymer specific heat.

$\Delta H$ is polymer state change enthalpy. It takes following values:

- $\Delta H=+H_{\mathrm{F}}$ with the passage of melting (for $\left.T(x, t)=T_{\mathrm{f}}\right)$

- $\Delta H=-H_{C}$ with the passage of crystallization (for $\left.T(x, t)=T_{\mathrm{C}}\right)$;

- $\Delta H=0$ everywhere else (for $T(x, t) \neq T_{\mathrm{f}}$ and $T_{\mathrm{C}}$ ).

Figure 6 shows the theoretical results obtained by our calculations and juxtaposed with those measured in experiments concerning PA11 part. We thus simulated the phase change appearing on the pseudo-stages obtained by the enthalpy method (layer to layer). The average relative error on temperature was found to be about $4.03 \%$.

\section{Cooling simulation (Ozawa model with Duffo's approach)}

In this case cooling can be described by the Ozawa formalism as presented in Eq. 2. The corresponding heat can be written by:

$\delta T_{\mathrm{C}}=\frac{\Delta H}{C_{\mathrm{p}}} \frac{\partial X_{\mathrm{t}}(x)}{\partial x} \delta x$ where, $\Delta H$ is the polymer state change enthalpy, $C_{\mathrm{p}}$ is the polymer heat capacity, $\delta x$ is the distance variation ( $n$ layer in polymer) and $X_{\mathrm{t}}$ is the Crystallinity ratio that directly depends on cooling rate function $K(T)$.

It is calculated according to the Duffo's approach [32] which can be used in average cooling rate (rotational moulding case).

Duffo has proposed to use a polynomial of the fourth order to approximate $K(T)$ as following relationship:

$\ln K(T)=A+B T+C T^{2}+D T^{3}+E T^{4}$

$T$ is temperature, $A, B, C, D$ and $E$ is specific coefficients for each polymer. The determination of $K(T)$ requires the deduction of the experimental points starting from measurements obtained by DSC tests for the high temperatures and of the theoretical points, calculated according to the Duffo's approach, for the low temperatures.

The values of their coefficients are listed in Table 4 and 5.

Therefore, the Ozawa equation can be introduced in the heat transfer model by combining the two Eqs 14 and 15 .

Figure 7 shows the plot of $K(T)$ as a function of temperature by applying experimental data and Duffo's approach in cooling rate $\phi$ of $10{ }^{\circ} \mathrm{C} \mathrm{min}^{-1}$. We can observe that Duffo's approach reproduces the same experimental data; subsequently, it is possible to calculate the evolution of the crystallinity rate at all cooling rate, using Ozawa's equation to make a comparison with the experimental results.

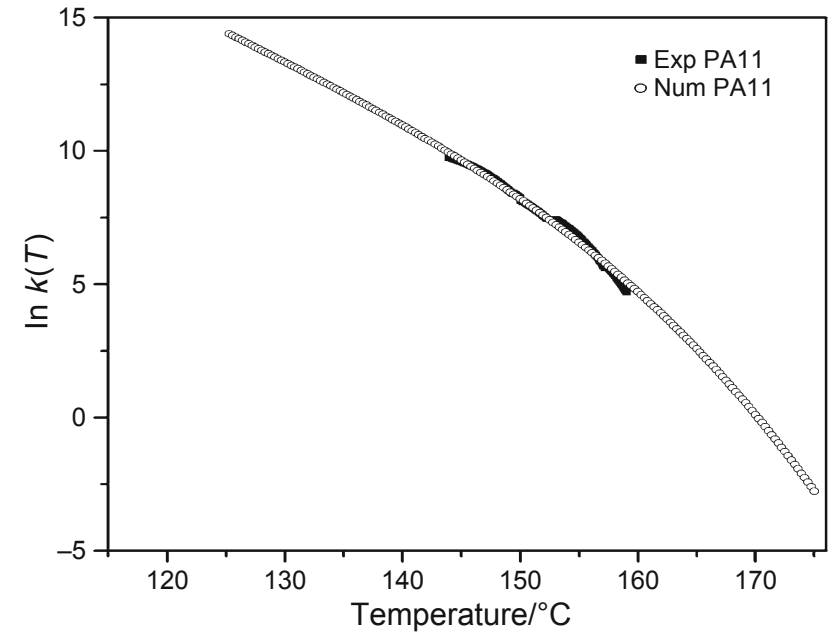

Fig. 7 Evolution of $K(T)$ as a function of temperature, experimental data and Duffo's approach

Table 5 Polynomial Duffo coefficients in the case of rotational moulding PA6 grade at $\phi=10{ }^{\circ} \mathrm{C} \mathrm{min}{ }^{-1}$

\begin{tabular}{llllll}
\hline Polymer & A & B & C & D & E \\
\hline PA11 & 34.5349160 & 0.5111350 & -0.0147000 & 0.0001110 & -0.0000002 \\
\hline
\end{tabular}




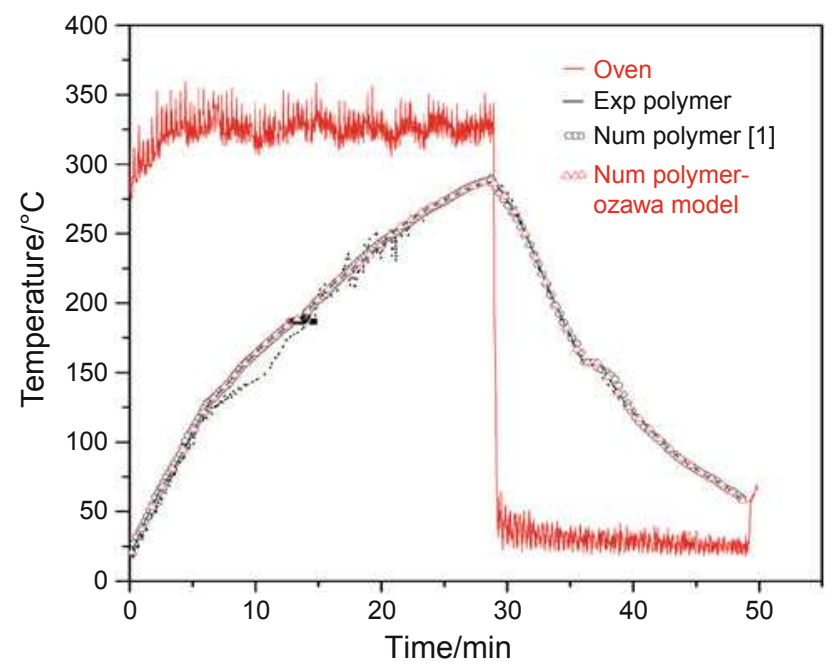

Fig. 8 Temperature versus time (T/t) diagram of PA11 according to enthalpy method (layer to layer), Ozawa model and experimental one

Figure 8 shows the theoretical results obtained by our calculations and juxtaposed with those measured in experiments concerning PA11 part. We thus simulated the phase change appearing on the cooling pseudo-stage obtained by coupling the enthalpy method (layer to layer) with Ozawa model with Duffo approach. The average relative error on temperature was found to be about $2.03 \%$. In fact, with Ozawa model the crystallization pseudo-stage is well simulated than when we use only enthalpic method.

In addition to the significant and interesting results obtained by the enthalpy method, until a certain limit, we note that crystallization kinetic model application makes significant corrections and improvements as for crystallinity rate evolution.

\section{Conclusions}

This paper has presented a thermal model which permits to follow the local evolution of the temperature in various areas of rotational moulding of polyamides PA11. The developed model considers the thermal variations which are developed in rotational moulding pieces and takes melting and crystallization into account. The tested thermal model, by the enthalpic method, reproduces the temperature evolution in the polymer part taking into account the existence of the melting and crystallization pseudo-stages. However, the model in this case does not represent the real temperature evolution especially the crystallization pseudo-stage. The last is well represented by introducing the Ozawa equation, and the model became more efficient. The crystallization pseudo-stage was advantageously restored by crystallization kinetic model (Ozawa), which takes into account two equations, namely the heat release equation and that of Ozawa's approach. Hence, the error between the experimental results and those obtained by the Ozawa combined with thermal model is reduced and the developed model in this case allows us to study the heat release during the crystallization process according to the crystallinity transformation rate.

\section{References}

1. Crawford RJ. Rotational moulding of plastic. 2nd ed. Wiley and Sons: Research Studies Press Ltd; 1996. p. 3-9.

2. Aramazotti D. Rotational moulding. In: Miller E, editor. Plastics products design handbook. New York: Marcel Dekker; 1983.

3. Xin W, Harkin-Jones EH, Crawford RJ, Fatnes AM. Rotational moulding of metallocene polyethylenes. Plast Rubber Compos. 2000;29:340-8.

4. Tcharkhtchi A, Barcelo P, Mazabraud P, Jousse F, Kearns MP. Study of adhesion between two layers in multilayers rotomolded products. Adv Eng Mater. 2002;4:475-8.

5. Oliveira MJ, Cramez MC. Rotational molding of polyolefins: processing, morphology, and properties. J Macromol Sci Phys. 2001;40:457-71.

6. Kontopoulou M, Bisaria M, Vlachopoulos J. An experimental study of rotational molding of polypropylene/polyethylene copolymers. Int Polym Process. 1997;12:165-73.

7. Greco A, Maffezzoli A, Calò E, Massaro C, Terzi R. An investigation into sintering of PA6 nanocomposite powders for rotational moulding. J Therm Anal Calorim. 2011; doi:10.1007/s10973-0111916-8.

8. Crawford RJ, Gibson S. Rotational moulding: the basis for designers. http://file.seekpart.com/keywordpdf/2011/1/12/201111 252045548.pdf. Accessed 17 July 2012.

9. Spence AG, Crawford RJ. The effect of processing variables on the formation and removal of bubbles in rotationally moulded products. Polym Eng Sci. 1996;36:993-1009.

10. Kontopoulou M, Vlachopoulos J. Melting and densification of thermoplastic powders. Polym Eng Sci. 2001;41:155-69.

11. Hu X, Bellehumeur CT. Modeling the morphology development of ethylene copolymers in rotational moulding. J Appl Polym Sci. 2006;102:5903-17.

12. Crawford RJ, Nugent PJ. Impact strength of rotationally moulded polyethylene articles. Plast Rubber Compos Process Appl. 1992; 17:33-41.

13. Greco A, Maffezzoli A. Powder shape analysis and sintering behavior of high density polyethylene powders for rotational molding. J Appl Polym Sci. 2004;92:449-60.

14. Tcharkhtchi A, Chinesta F, Pérot E. Simulation of thermal phenomena on the interface molten polymer during rotational molding. Int Polym Process. 2004;19:296-302.

15. Zhou Y, Fernandez-Pello AC. An enthalpy-temperature hybrid method for solving phase-change problems and its application to polymer pyrolysis and ignition. Combust Theory Model. 2000;4: 477-93.

16. Greco A, Maffezzoli A, Vlachopoulos J. Simulation of heat transfer during rotational molding. Adv Polym Tech. 2003;22:271-9.

17. Ozawa T. Kinetics of non-isothermal crystallization. Polymer. 1971;12:150-8.

18. Frank HP. Some oxidation characteristics of polypropylene. J polym sci. 1976;57:311-8. 
19. Greco A, Maffezzoli A. Polymer melting and polymer powder sintering by thermal analysis. J Therm Anal Calorim. 2003;72:1167-74.

20. Wunderlich B. Termination of crystallization or ordering of flexible, linear macromolecules. J Therm Anal Calorim. 2012;. doi:10.1007/s10973-012-2326-2.

21. Cebeci T. Convective heat transfer. Springer: Horizons publishing; 2002

22. Crank J, Nicolson P. A practical method for numerical evaluation of solutions of partial differential equations of the heat conduction type. Proc Camb Philos Soc. 1947;43:50-67.

23. Thomas JW. Numerical partial differential equations: finite difference methods. Texts in applied mathematics 22. New York: Springer-Verlag; 1995.

24. Wilmott P, Howison S, Dewynne J. The Mathematics of Financial Derivatives. A Student Introduction. Cambridge: Cambridge University Press; 1995.

25. Sarrabi S, Colin X, Tcharkhtchi A. Dégradation thermique du polypropylène au cours du rotomoulage. Matériaux et Techniques. 2008;96:253-61.
26. Van Krevelen DW. Properties of polymers. Amerstadem: Elsevier Scientific Publishing; 1976.

27. Williams JCL. In nylon plastics handbook. New York: Hanser Publishers; 1995.

28. Gogos G, Olson LG, Liu X, Pasham VR. New models for rotational molding of plastics. Polym Eng Sci. 1998;38:1387-98.

29. Gogos G, Olson LG, Liu X. Cycle time predictions for the rotational molding process with and without mold/part separation. Polym Eng Sci. 1999;39:617-29.

30. Bouralis J, Maeder G. Elaboration-structure-propriétés normalisation. Paris: Afnor-Nathan; 1997.

31. Facy G, Pompidou M. Méthodologie, production et normalisation. Paris: Afnor-Nathan; 1992.

32. Duffo P, Monasse B, Haudin JM. Cast film extrusion of polypropylene. Thermomechanical and physical aspects. J Polym Eng. 1991;10:151-229. 